\title{
The research context of GIIP - International and Interinstitutional Research Group in Art, Science and Technology
}

\author{
Keywords \\ Assistive interface, Collaborative work, Interdisciplinarity, Neuroscience for Art, Research Group
}

The GIIP “Interinstitutional and International Research Group on Art, Science and Technology" was certified at CNPq by UNESP in 2010. It isdirected by Rosangella Leote and Fernanda Duarte. We have developed investigation that are allocated in six research lines which are coordinated by Brazilian and foreign researchers. We aim to focus on works of art with emerging media where can be observed transductions, at any level, between the three areas that entitle the group, taking into account the contributions of these different fields, in an interdisciplinary way, but prospecting transdisciplinary emergence. This group is linked to the research line "Artistic processes and procedures" of the Post Graduate Program in Arts, (level 5/CAPES), at the Institute of Arts at UNESP (SP/Brazil); the activities take place within the Laboratory of Art, Science and Technology.The dynamic of the work brings together and leads to masters, doctoral and post-doctoral degrees. The participation of undergraduate and graduate students takes place, both by invitation among peers and voluntary adherence, as well as through the role of research guidance for Cls (PIBIC CNPq/UNESP/FAPESP), masters, doctorates (CAPES, FAPESP or without scholarship) and supervision (with or without scholarship, Brazilians or foreigners) of post-docs and co-tutorships, in addition to technical and monitoring activities (scholarship BAAE I and II UNESP).GIIP brings together 49 people, including permanent researchers, students, technicians or collaborators. The network comprises researchers in National territory (Public IES), and in international territory (through exchange agreements).
The group is continually open to the involvement of new researchers, collaborators or listeners, in its weekly meetings, with part of the team presential and another via the internet. Due to the pandemics, all activities are being carried out online. In addition to artistic activities, our intellectual production involves publications, conferences, seminars, lectures, exhibitions, international exchanges agreements, development of assistive interfaces with intellectual property, transference of technology and patent registration (in process at UNESP).One of the important results obtained has been the development of the "Zonas de Compensação/Compensation Zones" extension project, also international. It is a project that opens our results in research that crosses the edge of the University and reaches the non-academic society. There are other extension activities that are developed by GIIP, which we consider to be very well received. GIIP's original lines of research have been changing over time, a symptom of the evolution of investigation. Today they are Creation in Art and Science; Assistive interfaces for the arts: from diffusion to inclusion; Neuroscience for Art - Art for Neuroscience; Visual and special effects in audiovisual and shows; Poetics of space and time; and Art/Education Methodologies for people with disabilities.As the group's research processes involve the collaboration of several Brazilian and foreign universities, interdisciplinary, collaborative and individual projects are developed. They are investigative and/or extensive. The group's synergy impacts the production of its individuals, transforming and expanding their research objects and career paths. 